\title{
Management of hyperkalemia during treatment with mineralocorticoid receptor blockers: findings from esaxerenone
}

\author{
Hiromi Rakugi ${ }^{1} \cdot$ Satoru Yamakawa ${ }^{2} \cdot$ Kotaro Sugimoto $^{3}$
}

Received: 11 August 2020 / Revised: 29 September 2020 / Accepted: 29 September 2020 / Published online: 20 November 2020

(c) The Author(s) 2020. This article is published with open access

\begin{abstract}
The nonsteroidal mineralocorticoid receptor (MR) blocker esaxerenone has demonstrated good antihypertensive activity in a variety of patients, including those with uncomplicated grade I-III hypertension, hypertension with moderate renal dysfunction, hypertension with type 2 diabetes mellitus with albuminuria, and hypertension associated with primary aldosteronism. Hyperkalemia has long been recognized as a potential side effect occurring during treatment with MR blockers, but there is a lack of understanding and guidance about the appropriate management of hyperkalemia during antihypertensive therapy with MR blockers, especially in regard to the newer agent esaxerenone. In this article, we first highlight risk factors for hyperkalemia, including advanced chronic kidney disease, diabetes mellitus, cardiovascular disease, age, and use of renin-angiotensin-aldosterone system inhibitors. Next, we examine approaches to prevention and management, including potassium monitoring, diet, and the use of appropriate therapeutic techniques. Finally, we summarize the currently available data for esaxerenone and hyperkalemia. Proper management of serum potassium is required to ensure safe clinical use of MR blockers, including awareness of at-risk patient groups, choosing appropriate dosages for therapy initiation and dosage titration, and monitoring of serum potassium during therapy. It is critical that physicians take such factors into consideration to optimize MR blocker therapy in patients with hypertension.
\end{abstract}

Keywords Esaxerenone $\cdot$ Mineralocorticoid receptor blocker $\cdot$ Hypertension $\cdot$ Hyperkalemia management

\section{Introduction}

Mineralocorticoid receptor (MR) blockers are a class of drugs used in the treatment of essential hypertension and hyperaldosteronism and have antihypertensive effects in patients with low-renin or refractory (resistant) hypertension; these effects improve prognosis in patients with heart

Supplementary information The online version of this article (https:// doi.org/10.1038/s41440-020-00569-y) contains supplementary material, which is available to authorized users.

Hiromi Rakugi

rakugi@geriat.med.osaka-u.ac.jp

1 Department of Geriatric and General Medicine, Osaka University Graduate School of Medicine, 2-2 Yamadaoka, Suita, Osaka 565-0871, Japan

2 Clinical Development Department III, R\&D Division, Daiichi Sankyo Co., Ltd., 1-2-58, Hiromachi, Shinagawa-ku, Tokyo 140-8710, Japan

3 Medical Science Department, Daiichi Sankyo Co., Ltd., 3-5-1, Nihonbashi Honcho, Chuo-ku, Tokyo 103-8426, Japan failure [1-9]. A recent meta-analysis of data from 3.2 million patients indicated a high prevalence and worldwide burden of resistant hypertension and a need for new and more effective treatments [10]. The first MR blocker identified was spironolactone, a nonselective agent that also had affinity for progesterone and androgen receptors; this lack of selectivity and non-MR blocking activity contributed to the occurrence of problematic adverse events, including menstrual abnormalities in women and sexual dysfunction with painful gynecomastia in men [11-13]. Eplerenone, a second-generation MR blocker, had improved specificity for the MR, thus reducing the frequency of serious sex hormone-related adverse events [14-16]. More recently, the highly selective nonsteroidal MR blockers esaxerenone, finerenone, apararenone, and AZD9977 have been successively developed [17-21].

Among the nonsteroidal MR blockers, esaxerenone (MINNEBRO ${ }^{\circ}$, Daiichi Sankyo Co., Ltd.) was approved in Japan in January 2019 for the treatment of hypertension $[22,23]$. In vitro studies showed that esaxerenone specifically inhibits the binding of aldosterone to MR and does not have agonistic or antagonistic effects on glucocorticoid, 
androgen, or progesterone receptors, even at high concentrations [24]. Owing to the high MR specificity of esaxerenone, the incidence of sex hormone-related adverse events in phase III studies was very low (overall safety assessment: 2/1,250 [0.16\%]; Daiichi Sankyo Co., Ltd., unpublished data).

Esaxerenone has demonstrated good antihypertensive activity in a variety of patients, including those with uncomplicated grade I-III hypertension, hypertension with moderate renal impairment, hypertension with type 2 diabetes mellitus with albuminuria, and hypertension associated with primary aldosteronism (Daiichi Sankyo Co., Ltd., unpublished data, J305 and J307 studies; and published data [25-28]). The currently available clinical study data are summarized in Table 1 . Esaxerenone $2.5 \mathrm{mg} /$ day has been shown to be noninferior to eplerenone $50 \mathrm{mg} /$ day with respect to antihypertensive effects [25]. The antihypertensive effects of esaxerenone persisted throughout 52 weeks of treatment even when used as a monotherapy or when it was administered as an add-on therapy with reninangiotensin system (RAS) inhibitors or calcium channel blockers (CCBs) [27]. In addition to its antihypertensive effects in hypertensive patients with type 2 diabetes and albuminuria, renoprotective effects have also been reported, with the urinary albumin/creatinine ratio decreasing by $32.4 \%$ from baseline during treatment with $5 \mathrm{mg} /$ day esaxerenone, even in the presence of RAS inhibitors [26]. Similar antihypertensive and renoprotective effects have been observed in patients with moderate kidney dysfunction (Daiichi Sankyo Co., Ltd., unpublished data, J305 study). In contrast, eplerenone is contraindicated for hypertensive patients with moderate renal impairment and those with type 2 diabetes mellitus with albuminuria [16].

Thus, MR blockers have an important role in the management of hypertension, particularly in patients who cannot achieve adequate blood pressure reduction. Hyperkalemia is, however, recognized as a potential side effect during treatment with MR blockers [14, 15, 29, 30]. Publication of data from the Randomized Aldactone Evaluation Study showed that spironolactone reduced mortality by $30 \%$ compared with the mortality rate associated with placebo in patients with severe heart failure already receiving angiotensin-converting enzyme (ACE) inhibitors [6]. As a consequence, a marked increase in the prescription of spironolactone was observed in Canada [31]; however, this increase was associated with an increase in hyperkalemiarelated hospitalizations and deaths [31]. Regarding esaxerenone, during the phase III clinical studies conducted in Japan, blood potassium increased was the most common side effect (occurring in $4.1 \%$ of patients) [32]. As such, concerns about the occurrence of hyperkalemia during therapy are growing, but there is a lack of understanding and guidance about the appropriate management of hyperkalemia during antihypertensive therapy with MR blockers, especially with the newer agent esaxerenone. Therefore, this article highlights risk factors for hyperkalemia and approaches for its prevention and management and summarizes currently available data for esaxerenone.

\section{Definitions of hyperkalemia}

Definitions of hyperkalemia vary by geographic region. In Europe, mild hyperkalemia is defined as serum potassium $5.0-5.4 \mathrm{mEq} / \mathrm{L}$, moderate as $5.5-5.9 \mathrm{mEq} / \mathrm{L}$, and severe as $\geq 6.0 \mathrm{mEq} / \mathrm{L}$ [33]. The American Heart Association uses cutoffs of $5-6 \mathrm{mEq} / \mathrm{L}$ (mild), $6-7 \mathrm{mEq} / \mathrm{L}$ (moderate), and $>7 \mathrm{mEq} / \mathrm{L}$ (severe) [34]. However, in this review, we refer to the standard potassium values specified in the guidelines published by the Japanese Ministry of Health, Labor and Welfare entitled "Classification criteria for the seriousness of adverse drug reactions of medical agents", wherein serum potassium values of $\geq 5.5 \mathrm{mEq} / \mathrm{L}$ and $<6.0 \mathrm{mEq} / \mathrm{L}$ are classified as Grade 2 adverse drug reactions (ADRs), and values of $\geq 6.0 \mathrm{mEq} / \mathrm{L}$ are classified as Grade 3 ADRs [35]. For patients with chronic kidney disease (CKD), Japanese nephrology guidelines recommend maintaining serum potassium between 4.0 and $5.5 \mathrm{mEq} / \mathrm{L}$ to avoid hypo- or hyperkalemia [36]. Of note, mild to moderate hyperkalemia generally cannot be diagnosed from electrocardiogram (ECG) changes; a study in hospitalized patients indicated that the first ECG changes occurred at serum potassium levels above $7.2 \mathrm{mEq} / \mathrm{L}$ [37], a level that already indicates severe hyperkalemia [33, 34].

\section{Hyperkalemia risk factors and prognosis}

\section{Prognosis}

Potassium homeostasis regulates antiarrhythmic effects, maintenance of diastolic function, vasodilation, and reduction of thrombosis and atherosclerosis [38]. Thus, disturbed potassium homeostasis is associated with a number of adverse events. High potassium levels are associated with myocardial infarction, cardiac hyperexcitability and depression, neuromuscular manifestations (including paresthesia, muscle cramps, and muscle weakness), and gastrointestinal symptoms (including nausea and vomiting) [39-44]. Low potassium levels are also associated with muscle weakness and fatigue, as well as neurologic symptoms (including confusion and affective disorders), smooth muscle dysfunction (including paralytic ileus), arrhythmias and myocardial infarction, and even glucose intolerance [41, 43-47]. Collectively, the association between serum potassium levels and mortality shows a U-shaped 


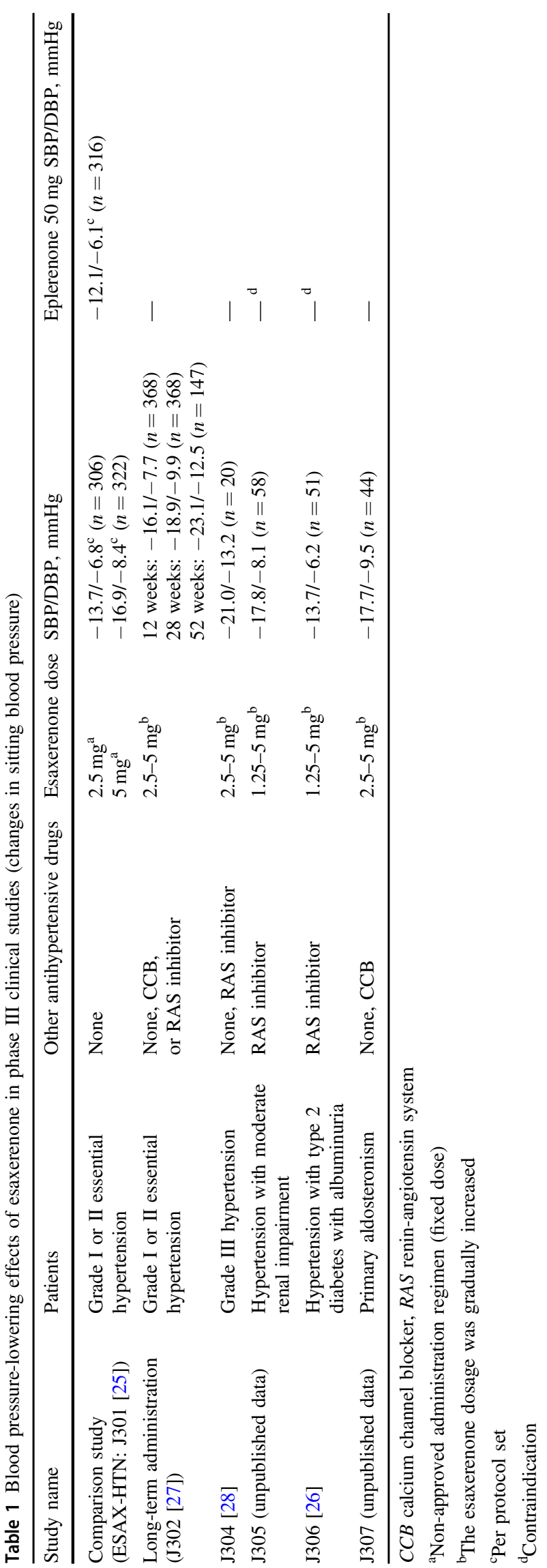

relationship, with increased mortality observed when serum potassium is either high or low [48]. In one analysis in patients with CKD (estimated glomerular filtration rate (eGFR) $<60 \mathrm{~mL} / \mathrm{min} / 1.73 \mathrm{~m}^{2}$ ), the pooled adjusted incidence rate ratios for patients with potassium levels $<3.5$ and $\geq 6.0 \mathrm{mEq} / \mathrm{L}$ were 3.05 (95\% confidence interval (CI) 2.53-3.68) and 3.31 (95\% CI 2.52-4.34), respectively [49].

Many studies have shown that very high serum potassium levels predispose patients to sudden death [50]. More recently, Kashihara et al. reported that in Japanese patients with CKD Stage 3 a with serum potassium $\geq 6.0 \mathrm{mEq} / \mathrm{L}$, the 3 -year mortality rate was $22.64 \%$ [51]. Hypokalemia (serum potassium $<4.0 \mathrm{mEq} / \mathrm{L}$ ) has also been reported to correlate with worse prognosis and increased mortality in patients with heart disease, with or without CKD [52, 53]. Specifically, in chronic heart failure patients, hypokalemia increases the risk of death [54]. Furthermore, compared with normokalemia, serum potassium levels $<3.5 \mathrm{mEq} / \mathrm{L}$ have been associated with an increased risk of developing atrial fibrillation (hazard ratio (HR) 1.63, 95\% CI 1.03-3.56) [55], while levels $<3.0 \mathrm{mEq} / \mathrm{L}$ induced a number of proarrhythmic changes, contributing to the occurrence of fatal ventricular arrhythmias and sudden cardiac death [56]. Therefore, clinicians need to be aware of the dangers of both hyperkalemia and hypokalemia.

\section{Risk factors}

Advanced CKD, diabetes mellitus, and cardiovascular disease (CVD) have all been identified as independent predictors of hyperkalemia [57]. In the real world, dehydration and diet may also be triggers for hyperkalemia [58]; dehydration is less likely in a clinical trial situation where patients are extensively screened for medical issues prior to inclusion. Finally, in general clinical practice, one of the most common risk factors for hyperkalemia is pharmacologic medication, including renin-angiotensin-aldosterone system inhibitors (RAASis) [59].

In a recently published Japanese study of hospital claims data from $>1$ million Japanese patients, $6.8 \%$ were found to have hyperkalemia [51]; this prevalence was found to be higher in patients with CKD (22.8\%), heart failure $(13.4 \%)$, diabetes $(10.8 \%)$, and hypertension $(10.8 \%)$. Furthermore, in patients receiving RAASi treatment, the incidence and prevalence of hyperkalemia (14.2\%) was higher than that in the general population [51].

\section{CKD (low eGFR)}

The kidney is usually the main route of potassium excretion; thus, in patients with CKD, urinary potassium excretion declines as the GFR decreases [60]. The frequency of hyperkalemia correlates with the level of renal function; in a 
multivariate analysis of elderly patients (aged $\geq 65$ years) with $\mathrm{CKD}$ and an eGFR $<60 \mathrm{~mL} / \mathrm{min} / 1.73 \mathrm{~m}^{2}$, the odds ratio (OR) for hyperkalemia increased by 1.26 for every $5 \mathrm{~mL} / \mathrm{min} / 1.73 \mathrm{~m}^{2}$ decrease in eGFR [61]. Similarly, data from 1,094 African American adults with hypertensive CKD showed an increased risk of hyperkalemia in patients with an eGFR of $<30$ or $31-40 \mathrm{~mL} / \mathrm{min} / 1.73 \mathrm{~m}^{2}$ versus those with an eGFR of $>50 \mathrm{~mL} / \mathrm{min} / 1.73 \mathrm{~m}^{2}$ (HR 3.61, 95\% CI 1.42-9.18; $p=0.007$ ) [62]. Furthermore, data from a retrospective cohort analysis indicated that during antihypertensive treatment with the MR blocker spironolactone, patients with $\mathrm{CKD}$ had a significantly higher rate of hyperkalemia $(>5.5 \mathrm{mEq} / \mathrm{L})$ than those without CKD $(5.7 \%$ vs. $0 \%)$ [63].

\section{Diabetes}

There are a number of mechanisms that contribute to a higher risk of developing hyperkalemia in patients with diabetes; these include impaired potassium excretion, impaired renal tubular function, and a reduced ability to shift potassium into cells [64]. Diabetes was identified as an independent predictor of hyperkalemia in a large retrospective cohort study conducted in the United States [65]. In a nested case-control study of CKD patients with or without diabetes, the presence of diabetes significantly increased the prevalence of hyperkalemia in patients with Stage 3 CKD (28.6\% vs. $17.5 \%$ in those without diabetes; $p=0.036$ ) [66]. In a recent registry study in Denmark, one in six patients with newly diagnosed diabetes experienced a hyperkalemic event within 4 years, and the development of hyperkalemia in patients with diabetes was associated with worse clinical outcomes and higher mortality rates [67].

\section{CVD}

Patients with heart failure are often older [68] and have a high prevalence of CKD [69], both of which are risk factors for the development of hyperkalemia [51, 70, 71]. Thus, in patients with heart failure, abnormalities in electrolyte levels, resulting from both the pathophysiologic changes underlying the disease and from the therapeutic regimens used in treatment, are a common and potentially hazardous complication [72, 73].

Based on data from a large retrospective cohort study of patients with CVD and CKD $(n=15,803)$, both coronary artery disease (HR 1.32, 95\% CI 1.21-1.43) and peripheral vascular disease (HR 1.55, 95\% CI 1.36-1.77) have been found to be predictors of hyperkalemia [57]. In a cohort of 19,194 patients with newly diagnosed heart failure followed for a mean of 3.9 years, 2,176 cases of hyperkalemia were identified (11.3\%) [74]. Significant risk factors included valvular heart disease (OR 1.28; 95\% CI 1.06-1.54), renal failure (OR 3.81; 95\% CI 3.29-4 .42), and diabetes (OR 1.52 ; $95 \%$ CI $1.31-1.75$ ), as well as the use of pharmacologic medication (including potassium-sparing diuretics (OR 3.01; 95\% CI 2.61-3.48) and ACE inhibitors (OR 1.70; 95\% CI 1.41-2.04)) [74].

\section{Age}

Distal renal tubule function and the ability to eliminate potassium decline as age increases [75-77]. As a result, elderly individuals are at increased risk of developing hyperkalemia, especially those who also have CKD or CVD [78]. In a group of patients with heart failure, the mean ( \pm standard deviation) age was significantly older in those with serum potassium $>5.0 \mathrm{mEq} / \mathrm{L}$ ( $76 \pm 9$ years) than in those with lower potassium levels $(73 \pm 11$ years) [79]. Similarly, in a retrospective study of patients with CVD and $\mathrm{CKD}$, patients with hyperkalemia were significantly older (66.1 \pm 10.3 years) than those with normal potassium levels (63.9 \pm 11.2 years) [57]. The results of another retrospective analysis using electronic medical records showed that older patients were at greater risk of developing hyperkalemia (serum potassium $>5.0 \mathrm{mEq} / \mathrm{L}$ ) than younger patients (OR $(95 \% \mathrm{CI})$ values for age $45-64,65-74$, and $\geq 75$ years versus age 18-44 years were 1.41 (1.36-1.47), 1.66 (1.59-1.73) and $1.72(1.65-1.79)$, respectively) [65].

\section{RAASi medication}

Treatment with antihypertensive agents, ACE inhibitors, angiotensin receptor blockers (ARBs), a direct renin inhibitor, and MR blockers are all known to increase the risk of hyperkalemia [59, 80, 81]. Elevated serum potassium levels are observed with single-agent administration, and the level increases further with combination therapy [82, 83]. A systematic review showed that a combination therapy with an ACE inhibitor and an ARB resulted in a small, but significant, increase in serum potassium levels (weighted mean difference, $0.11 \mathrm{mEq} / \mathrm{L} ; 95 \%$ CI 0.05-0.17) [84].

In a study of normokalemic patients with hypertension who were randomly assigned to treatment with the ACE inhibitor lisinopril, the diuretic chlorthalidone, or the $\mathrm{CCB}$ amlodipine, the incidence of hyperkalemia was found to be greater in the patients treated with lisinopril $(3.6 \%)$ than in those treated with either of the other agents $(p<0.01$ for both) [85]. In another study of patients with systemic hypertension, monotherapy with either the ACE inhibitor enalapril or the MR blocker eplerenone was associated with elevated serum potassium levels [86].

In patients with diabetes, multiple studies have reported that treatment with MR blockers [87, 88], ARBs [89, 90], ACE inhibitors [90], or a direct renin inhibitor [91] is associated with an increase in potassium levels and a risk of 
severe hyperkalemia in a small number of patients. In patients with systolic heart failure, large randomized studies investigating ACE inhibitors or ARBs have demonstrated significant increases in serum potassium during treatment. In one study, the mean serum potassium level increased by $0.2 \mathrm{mEq} / \mathrm{L}$ during treatment with enalapril, and the proportion of patients with a serum potassium level $>5.5 \mathrm{mEq} / \mathrm{L}$ was significantly higher in the enalapril group than in the placebo group $(6.4 \%$ vs. $2.5 \% ; p<0.01)$ [92]. Similarly, the rate of hyperkalemia leading to treatment discontinuation was higher in the candesartan group than in the placebo group in a large randomized controlled trial (RCT) $(1.9 \%$ vs. $0.3 \% ; p=$ 0.0005) [93].

Combination therapy has the potential to further worsen the risk of hyperkalemia. In one study, the addition of spironolactone or losartan to ACE inhibitor therapy in patients with hypertension, diabetes, and albuminuria was associated with significant increases in serum potassium level compared to the outcome in the placebo group ( $p<0.0001$ and $p=0.03$, respectively) [94]. In parallelgroup RCTs of spironolactone added to an ACE inhibitor and/or ARB, increases in serum potassium ranged between 0.1 and $0.8 \mathrm{mEq} / \mathrm{L}[6,88,94-97]$. Corresponding increases in serum potassium in crossover RCTs were $0.1-0.3 \mathrm{mEq} / \mathrm{L}$ [87, 98-100], and in nonrandomized trials, they were $0.1-0.4 \mathrm{mEq} / \mathrm{L}$ [101-104].

\section{Management of hyperkalemia in hypertension}

To ensure patient safety, it is important to monitor and manage potassium at a personalized level owing to interindividual variations in risk, symptoms, and treatments.

\section{Monitoring}

In the general patient population, potassium levels are often elevated. Approximately $6.8 \%$ of the Japanese population is estimated to have hyperkalemia (defined as at least two serum potassium readings $\geq 5.1 \mathrm{mEq} / \mathrm{L}$ ) based on the results of a medical database analysis [51]. Similarly, a Swedish study examining 364,955 patients who accessed healthcare over a 3-year period revealed a $7 \%$ incidence of hyperkalemia (defined as potassium $>5 \mathrm{mEq} / \mathrm{L}$ ) with a $35.7 \%$ rate of recurrence [105].

Regular monitoring allows drug dosages to be adjusted based on serum potassium levels. A long-term potassium monitoring study in patients with heart failure suggested that maintenance of serum potassium levels within the normal range should be considered a therapeutic target, allowing clinicians to modify treatment and mitigate risks to improve clinical outcomes for patients [79]. In patients with diabetes being treated with an ACE inhibitor, ARB, or spironolactone, compared with no monitoring, regular monitoring of serum potassium has been shown to decrease the risk of hyperkalemia-related adverse events (adjusted relative risk 0.5 , 95\% CI 0.37-0.66) [64]. According to the Kidney Disease Outcomes Quality Initiative [106], the suggested frequency of serum potassium monitoring after initiation of ACE inhibitor or ARB therapy is as follows: every $4-12$ weeks for serum potassium $\leq 4.5 \mathrm{mEq} / \mathrm{L}$, every 2-4 weeks for $4.6-5 \mathrm{mEq} / \mathrm{L}$, and more frequently than every 2 weeks for $>5 \mathrm{mEq} / \mathrm{L}$. The American Heart Association states that potassium levels and renal function should typically be checked on days 3 and 7 after initiating therapy with aldosterone antagonists and then at least monthly for the first 3 months [107]. However, the frequency of serum potassium measurement is not described in the guidelines published by the Japanese Society of Nephrology [36] or Japanese societies related to CVD [108].

To avoid the risk of false positive findings, serum potassium levels need to be measured carefully [109]. Causes of false positives include hemolysis, delay in sample processing, long-term cold storage, and contamination of blood samples with antiseptics or potassium salts from blood collection tubes [110, 111]. Careful collection techniques and proper sample handling and storage are therefore essential.

Additional suggestions for clinicians intending to prescribe RAASis include pretreatment GFR and baseline serum potassium determination (to identify or exclude highrisk patients), dosage titration, and discontinuation of potassium supplements [107] or concomitant maintenance treatment with loop or thiazide diuretics [112].

\section{Diet}

Restricting the intake of potassium-rich foods is also effective in preventing hyperkalemia, and restricting dietary potassium intake is particularly important for patients with renal impairment [113]. According to Japanese dietary recommendations for CKD [114], although there is no specific limit for patients with CKD Stages 1-3a (eGFR $\geq$ $45 \mathrm{~mL} / \mathrm{min} / 1.73 \mathrm{~m}^{2}$ ), daily potassium intake should be limited to $\leq 2,000 \mathrm{mg} /$ day for patients with Stage $3 \mathrm{~b}$ (eGFR 30 to $<45 \mathrm{~mL} / \mathrm{min} / 1.73 \mathrm{~m}^{2}$ ) and to $\leq 1,500 \mathrm{mg} /$ day for patients with Stages 4 or $5\left(\right.$ GFR $\left.<30 \mathrm{~mL} / \mathrm{min} / 1.73 \mathrm{~m}^{2}\right)$. In adults with Stages 3-5d and posttransplant patients with a normal potassium range, the National Kidney Foundation suggests that it is reasonable to adjust the dietary potassium intake to maintain levels within the normal range, but if this population exhibits hyperkalemia, their dietary potassium level should be reduced for the adjustment of serum potassium levels [115]. Clinicians should, therefore, be aware of foods that are high or low in potassium. For example, the potassium content of syrup, vegetable oils, and 
shortenings is zero [116], while that of dairy products, fruits such as bananas and pineapples, and vegetables such as pumpkins and sweet potatoes is particularly high [113]. As a result, patients who are planning to adjust their potassium intake must limit the amount of these foods consumed. Conversely, a diet in which various food groups are extremely restricted will result in a lack of essential nutrients and may cause nutritional disorders [117]. In addition, even for the same food item, the amount of potassium consumed can vary depending on the cooking method utilized [113]. In the event that potassium limitation is deemed necessary, appropriate guidance should be provided in coordination with a registered dietician.

\section{Treatment}

Approaches to managing hyperkalemia depend upon symptom severity and include dietary potassium intake restriction, dosage adjustment of MR blockers and/or RAS inhibitors, promotion of potassium excretion from the body using diuretics, use of oral potassium adsorbent agents, such as calcium/sodium polystyrene sulfonate, promotion of potassium redistribution from extracellular to intracellular spaces via intravenous administration of insulin and glucose, cell membrane stabilization via intravenous administration of calcium solution, and hemodialysis [118-120].

For patients with mild hyperkalemia $(<6.0 \mathrm{mEq} / \mathrm{L})$ without ECG changes, a reduced potassium intake and discontinuation of potassium-elevating drugs may be sufficient to normalize potassium levels [118]. Strategies to remove potassium from the body, such as the use of loop diuretics and oral potassium adsorbent agents, should be considered for emergent or symptomatic hyperkalemia [58]. Administration of sodium polystyrene sulfonate causes gastrointestinal excretion of potassium, but careful monitoring is necessary as the rate of excretion may be unpredictable [118].

These same procedures are generally also effective for severe hyperkalemia ( $>6.5 \mathrm{mEq} / \mathrm{L})$ without ECG changes. If more aggressive therapy is required, potassium can be redistributed using insulin and glucose, with a peak occurring $60 \mathrm{~min}$ after administration and continuing for several hours [118]; however, these agents may be contraindicated in patients with certain comorbidities. During insulin administration, glucose is administered simultaneously to prevent hypoglycemia caused by increased uptake of glucose alongside potassium. For severe hyperkalemia $(>6.5 \mathrm{mEq} / \mathrm{L})$, particularly in patients with cardiomyocyte damage in whom an ECG trace shows the loss of P-wave or QRS widening, treatment with intravenous calcium to antagonize the action of potassium in the heart may also be indicated [118]. In emergency cases, hemodialysis is necessary.

\section{Esaxerenone and hyperkalemia}

A summary of the incidence of serum potassium elevation occurring in phase III clinical trials of esaxerenone is provided in Table 2. These trials included patients with essential hypertension, hypertension with moderate renal impairment, hypertension with type 2 diabetes and albuminuria, and primary aldosteronism, and esaxerenone was given alone or in combination with RAS inhibitors or CCBs (Daiichi Sankyo Co., Ltd., unpublished data, J305, and J307 studies; and published data [25-28]). In these clinical studies, serum potassium elevation was defined as a serum potassium level $\geq 5.5 \mathrm{mEq} / \mathrm{L}$; this level was set to assure patient safety and to reduce the risk of patients developing dangerously high potassium levels of $\geq 6.0 \mathrm{mEq} / \mathrm{L}$.

Overall, in the phase III studies, the incidence of blood potassium increased as a side effect was $4.1 \%(51 / 1,250$ patients), and of these patients, $1.7 \%$ (21/1,250 patients) had serum potassium levels $\geq 5.5 \mathrm{mEq} / \mathrm{L}$ [32]. There were no notable differences between the incidence rates of serum potassium elevation observed with esaxerenone and those reported for eplerenone and spironolactone. In patients with hypertension without severe renal impairment or diabetes who received monotherapy, increases in potassium levels $\geq 5.5 \mathrm{mEq} / \mathrm{L}$ occurred in $3.0-5.7 \%$ of esaxerenone-treated patients [25, 27], compared with $1.8-3.0 \%$ of eplerenonetreated patients $[25,121]$. In this same patient population, when administered in combination with a RAS inhibitor or $\mathrm{CCB}$, potassium levels $\geq 5.5 \mathrm{mEq} / \mathrm{L}$ occurred in $3.4-6.3 \%$ [27] and $0-1.2 \%$ [122] of esaxerenone- and eplerenonetreated patients, respectively. In patients with diabetes and albuminuria, potassium levels $\geq 5.5 \mathrm{mEq} / \mathrm{L}$ occurred in $3.9 \%$ of esaxerenone-treated patients [26] and in $4.8 \%$ of spironolactone-treated patients [98]. Although incidence rates of serum potassium elevation may appear to be slightly numerically higher for esaxerenone than for eplerenone, only a single phase III study in patients with essential hypertension and normal kidney function (J301 [25]) has conducted a direct comparison of esaxerenone and eplerenone within the same clinical trial, and no statistical analysis was conducted in regard to the rates of serum potassium elevation between esaxerenone and eplerenone in the study. Moreover, no comparator study exists for patients with severe renal impairment or diabetes. Thus, regarding the incidence of hyperkalemia, the superiority or inferiority of either of these agents over the other remains unproven.

Data for the time course of serum potassium levels during esaxerenone treatment are shown in Fig. 1. These study data indicate that increases in serum potassium levels occurred in the first 2 weeks after treatment initiation, without any additional increases at the time of esaxerenone 


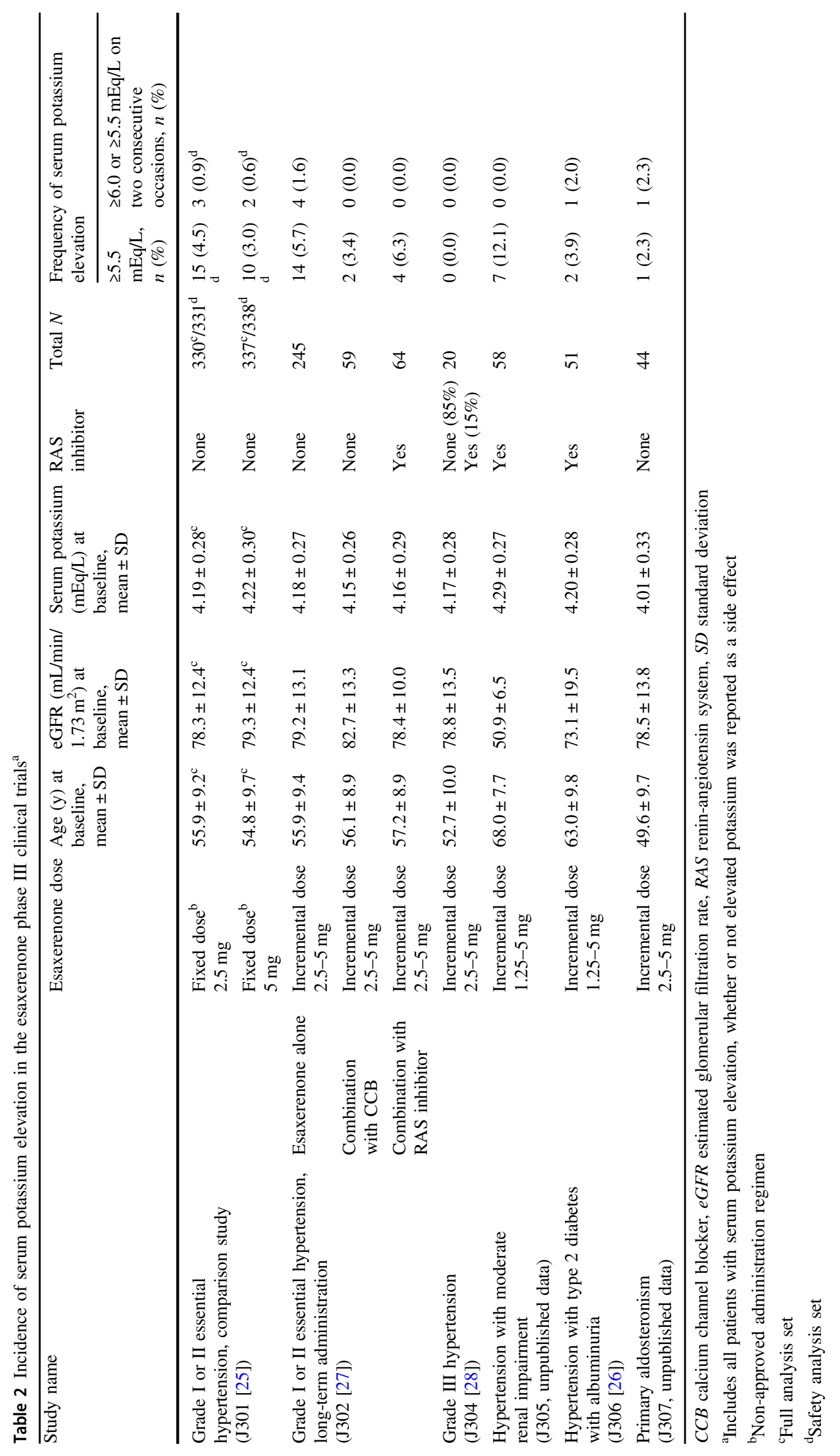


Fig. 1 Serum potassium levels over time according to treatment regimen. A Changes in serum potassium levels. B Changes in serum potassium from baseline. Black arrows indicate dose increases at weeks 4,6 , and 8 : 2.5-5 mg for the J302 [27] study and $1.25-2.5 \mathrm{mg}$ for the $\mathrm{J} 305$ (unpublished data) and J306 [26] studies. The gray arrow indicates dose increases at week 8: $2.5-5 \mathrm{mg}$ for the J305 (unpublished data) and J306 [26] studies. Solid lines indicate dose periods, and dotted lines indicate follow-up (no treatment) periods
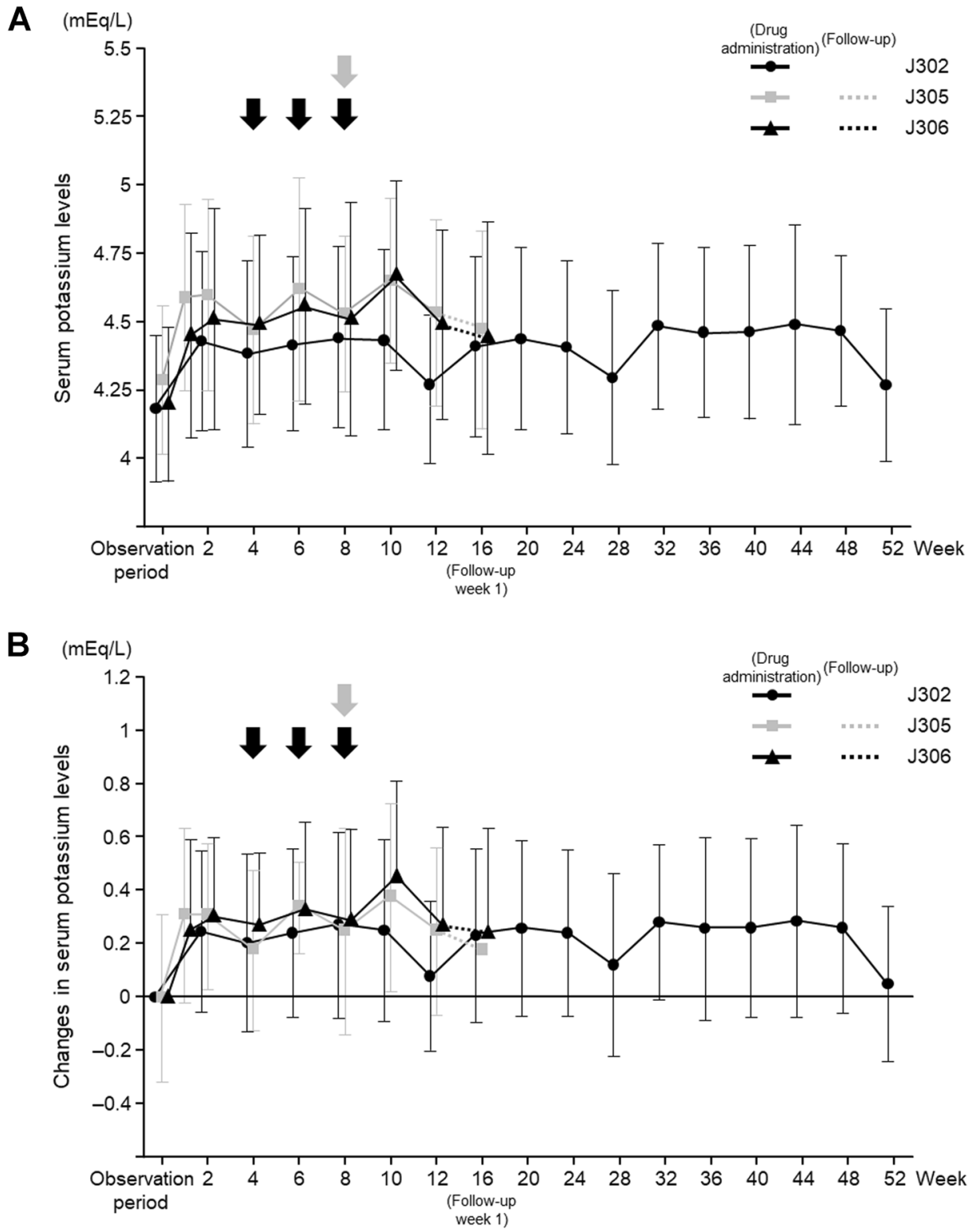

dose escalation [27]. There was no specific trend in the onset time of serum potassium elevation after 2 weeks of esaxerenone administration. Based on these data, the esaxerenone labeling recommendations suggest that potassium levels should be measured before treatment, at 2 and 4 weeks after treatment initiation (or during any up- or down-titration), and regularly thereafter [22]. Similarly, studies of eplerenone in patients with heart failure demonstrated that elevated potassium levels were detectable within the first 1-4 weeks after treatment initiation [123, 124], and a study of spironolactone in patients with CKD also indicated that serum potassium increased within the first 4 weeks of treatment [125].

The profile of serum potassium levels following esaxerenone treatment remained consistent in high-risk patient groups (i.e., those with moderate renal dysfunction or diabetes with albuminuria) (Fig. 1) (Daiichi Sankyo Co., Ltd., unpublished data, J305 study; and published data, J306 study [26]). In patients with moderate renal impairment (J305) and type 2 diabetes and albuminuria (J306) [26], mean serum potassium levels increased following the initiation of esaxerenone treatment and after each dose escalation visit, but there was no clear trend towards a continuous increase over time. In the long-term administration study (J302), there was no association between duration of treatment and incidence of serum potassium elevation. The detailed timing of onset of serum potassium elevation is shown in Supplementary Table 1 (moderate renal impairment; unpublished data, J305), Supplementary Table 2 (type 2 diabetes and albuminuria [126]), and Supplementary Table 3 (long-term administration study [27]). 
There were no sex-related differences in the incidence of serum potassium elevation in esaxerenone-treated patients. There were also no differences in rates of serum potassium elevation during esaxerenone therapy according to body weight, liver function, or use of a RAS inhibitor (even though, as described earlier, RAS inhibitors alone have been shown to increase the risk of elevated serum potassium level) (Supplementary Table 4). Regarding liver function, mild to moderate hepatic impairment was shown to have no clinically relevant effect on esaxerenone exposure [127]. Conversely, increased blood exposure of eplerenone was observed in patients with mild to moderate hepatic impairment, but this increase was not associated with the incidence of hyperkalemia [16, 128]. Thus, the liver function does not appear to be associated with serum potassium elevation.

Table 3 shows rates of serum potassium elevation in patient subgroups based on baseline serum potassium, baseline renal function, age, and presence of type 2 diabetes with albuminuria. The proportion of patients with serum potassium $\geq 5.5 \mathrm{mEq} / \mathrm{L}$ was higher among patients with baseline potassium levels $\geq 4.5$ than among those with baseline potassium levels $<4.5 \mathrm{mEq} / \mathrm{L}$ and in the subgroup with eGFR $<60 \mathrm{~mL} / \mathrm{min} / 1.73 \mathrm{~m}^{2}$ than in the subgroup with eGFR $\geq 60 \mathrm{~mL} / \mathrm{min} / 1.73 \mathrm{~m}^{2}$ (Table 3 ). Thus, it appears that serum potassium levels are more likely to be elevated if renal function is worse. However, neither baseline serum potassium nor eGFR had any effect on the proportion of patients with serum potassium $\geq 6.0$ or $5.5 \mathrm{mEq} / \mathrm{L}$ on two or more consecutive occasions. There was no clear trend in the occurrence of elevated potassium levels according to age $(<65, \geq 65$, or $\geq 75$ years) in esaxerenone-treated patients (Table 3). Nevertheless, because the renal function is known to decline with age, thorough monitoring is recommended in elderly patients. No tendency towards serum potassium elevation was observed in patients with type 2 diabetes and albuminuria (Table 3).

\section{Management of hyperkalemia during antihypertensive treatment with esaxerenone}

Clinical data from phase III studies showed that serum potassium levels returned to normal after withdrawal of esaxerenone, and no additional treatment was required. In the J301 and J302 studies, esaxerenone treatment was discontinued in five and four patients, respectively, with serum potassium measurements of $\geq 6.0$ or $\geq 5.5 \mathrm{mEq} / \mathrm{L}$ on two consecutive occasions. In all patients, potassium levels normalized within 28 days [25, 27].

Available clinical study data can be used to develop a profile of patients at higher risk of developing hyperkalemia, allowing appropriate selection of patients for esaxerenone therapy. Based on patient factors such as lower renal function (reduced eGFR, albuminuria) and older age, gradually increasing the esaxerenone dosage from 1.25 to $2.5-5 \mathrm{mg} /$ day has been suggested as a good strategy to reduce the risk of developing hyperkalemia compared with starting treatment at a fixed dosage [22].

An exposure-response analysis was performed using data from clinical studies where esaxerenone was given at a fixed dosage in patients with hypertension and diabetic nephropathy [126] or where the esaxerenone dosage was gradually increased in patients with moderate renal impairment or diabetic nephropathy (Daiichi Sankyo Co., Ltd., unpublished data, J305 study; and published data, J306 study [26]). The analysis showed that event rates of the first occurrence of hyperkalemia increased as esaxerenone mean exposure increased when the dosage was fixed but not when esaxerenone was initiated at a lower dosage with gradual upwards titration [129]. In fact, in hypertensive patients with type 2 diabetes and albuminuria, the proportions of patients with serum potassium $\geq 5.5 \mathrm{mEq} / \mathrm{L}$ and serum potassium $\geq 6.0$ or $5.5 \mathrm{mEq} / \mathrm{L}$ on two or more consecutive occasions were lower when esaxerenone was started at $1.25 \mathrm{mg} /$ day and then increased [26] than when therapy was started at a higher fixed dosage [126] (Table 4). These data indicate that incremental dosing of esaxerenone increased serum potassium to a lesser extent (i.e., up to 5.5 $\mathrm{mEq} / \mathrm{L}$ and rarely increased to $\geq 6.0$ or $5.5 \mathrm{mEq} / \mathrm{L}$ on two or more consecutive occasions) when compared with the fixed dosing method. Although similar decreases in the incidence rate of hyperkalemia were reported when eplerenone was administered starting at a lower dose that gradually increased [130], careful monitoring of serum potassium is required before initiation of and during any up- or downtitration regimen. In the recently published J306 study, esaxerenone was administered over 12 weeks at a starting dosage of $1.25 \mathrm{mg} / \mathrm{day}$ and was gradually titrated to 2.5 $\mathrm{mg} /$ day and $5 \mathrm{mg} /$ day at weeks 4,6 , or 8 based mainly on serum potassium levels but with reference to other patient factors such as eGFR and blood pressure [26]. In this case, 1/51 patients had consecutive serum potassium measurements $>5.5 \mathrm{mEq} / \mathrm{L}$, but this elevated level resolved following dosage reduction, indicating that careful monitoring and treatment modulation can be helpful in minimizing hyperkalemic risk. Because serum potassium increases may occur more frequently in patients with moderate renal dysfunction, it is desirable to monitor the values in patients with diabetes and albuminuria or proteinuria, elderly people, and patients with concomitant medications that induce hyperkalemia. As previously stated, the package insert recommends that serum potassium levels be measured before treatment initiation and at regular intervals thereafter [22]. 
Table 3 Patients at risk for serum potassium elevation ${ }^{\mathrm{a}}$

Stratified by baseline serum potassium

\begin{tabular}{|c|c|c|c|c|c|}
\hline Study name & Esaxerenone dose & $\begin{array}{l}\text { Baseline serum } \\
\text { potassium } \\
(\mathrm{mEq} / \mathrm{L})\end{array}$ & $N$ & $\begin{array}{l}\text { Serum potassium } \\
\geq 5.5 \mathrm{mEq} / \mathrm{L}, \\
n(\%)\end{array}$ & $\begin{array}{l}\text { Serum potassium } \geq 6.0 \\
\text { or } \geq 5.5 \mathrm{mEq} / \mathrm{L} \text { on two } \\
\text { consecutive occasions } \\
n(\%)\end{array}$ \\
\hline \multirow[t]{2}{*}{ J203 [131]/J301 [25] } & Fixed dose $\mathrm{b}^{\mathrm{b}}$ & $<4.5$ & 764 & $9(1.2)$ & $1(0.1)$ \\
\hline & $1.25-5 \mathrm{mg}$ & $\geq 4.5$ & 160 & $21(13.1)$ & $5(3.1)$ \\
\hline \multirow[t]{2}{*}{ J302 [27] } & Incremental dose & $<4.5$ & 310 & $11(3.5)$ & $2(0.6)$ \\
\hline & $2.5-5 \mathrm{mg}^{\mathrm{c}}$ & $\geq 4.5$ & 58 & $9(15.5)$ & $2(3.4)$ \\
\hline \multicolumn{6}{|c|}{ Stratified by renal function } \\
\hline Study name & Esaxerenone dose & $\begin{array}{l}\text { Baseline eGFR } \\
\left(\mathrm{mL} / \mathrm{min} / 1.73 \mathrm{~m}^{2}\right)\end{array}$ & $N$ & $\begin{array}{l}\text { Serum potassium } \\
\geq 5.5 \mathrm{mEq} / \mathrm{L} \\
n(\%)\end{array}$ & $\begin{array}{l}\text { Serum potassiu } \geq 6.0 \text { or } \\
\geq 5.5 \mathrm{mEq} / \mathrm{L} \text { on two } \\
\text { consecutive occasions, } \\
n(\%)\end{array}$ \\
\hline \multirow[t]{2}{*}{ J204 [126] } & Fixed dose $\mathrm{e}^{\mathrm{b}}$ & $\geq 30,<60$ & 100 & $21(21.0)$ & $7(7.0)$ \\
\hline & $0.625-5 \mathrm{mg}^{\mathrm{c}}$ & $\geq 60$ & 175 & $13(7.4)$ & $5(2.9)$ \\
\hline \multirow[t]{2}{*}{ J306 [26] } & Incremental dose & $\geq 30,<60$ & 15 & $1(6.7)$ & $0(0.0)$ \\
\hline & $1.25-5 \mathrm{mg}^{\mathrm{c}}$ & $\geq 60$ & 36 & $1(2.8)$ & $1(2.8)$ \\
\hline \multicolumn{6}{|l|}{ Stratified by age } \\
\hline Study name & Esaxerenone dose & $\begin{array}{l}\text { Baseline age } \\
\text { (years) }\end{array}$ & $N$ & $\begin{array}{l}\text { Serum potassium } \\
\geq 5.5 \mathrm{mEq} / \mathrm{L}, \\
n(\%)\end{array}$ & $\begin{array}{l}\text { Serum potassium } \geq 6.0 \\
\text { or } \geq 5.5 \mathrm{mEq} / \mathrm{L} \text { on two } \\
\text { consecutive occasions, } \\
n(\%)\end{array}$ \\
\hline \multirow[t]{3}{*}{ J203 [131]/J301 [25] } & Fixed dose ${ }^{b}$ & $<65$ & 742 & $22(3.0)$ & $2(0.3)$ \\
\hline & $1.25-5 \mathrm{mg}$ & $\geq 65$ & 182 & $8(4.4)$ & $4(2.2)$ \\
\hline & & $\geq 75$ & 24 & $3(12.5)$ & $1(4.2)$ \\
\hline \multirow[t]{3}{*}{ J302 [27] } & Incremental dose & $<65$ & 290 & $15(5.2)$ & $2(0.7)$ \\
\hline & $2.5-5 \mathrm{mg}^{\mathrm{c}}$ & $\geq 65$ & 78 & $5(6.4)$ & $2(2.6)$ \\
\hline & & $\geq 75$ & 6 & $0(0.0)$ & $0(0.0)$ \\
\hline \multirow{3}{*}{$\begin{array}{l}\mathrm{J} 305 \\
\text { (unpublished data) }\end{array}$} & Incremental dose & $<65$ & 17 & $1(5.9)$ & $0(0.0)$ \\
\hline & $1.25-5 \mathrm{mg}^{\mathrm{c}}$ & $\geq 65$ & 41 & $6(14.6)$ & $0(0.0)$ \\
\hline & & $\geq 75$ & 16 & $3(18.8)$ & $0(0.0)$ \\
\hline \multirow[t]{3}{*}{ J306 [26] } & Incremental dose $\mathrm{a}^{\mathrm{a}}$ & $<65$ & 27 & $1(3.7)$ & $0(0.0)$ \\
\hline & $1.25-5 \mathrm{mg}^{\mathrm{c}}$ & $\geq 65$ & 24 & $1(4.2)$ & $0(0.0)$ \\
\hline & & $\geq 75$ & 7 & $0(0.0)$ & $0(0.0)$ \\
\hline \multicolumn{6}{|c|}{ Stratified by type 2 diabetes with albuminuria } \\
\hline Study name & Esaxerenone dose & $\begin{array}{l}\text { Type } 2 \text { diabetes } \\
\text { with albuminuria }\end{array}$ & $N$ & $\begin{array}{l}\text { Serum potassium } \\
\geq 5.5 \mathrm{mEq} / \mathrm{L} \\
n(\%)\end{array}$ & $\begin{array}{l}\text { Serum potassium } \geq 6.0 \\
\text { or } \geq 5.5 \mathrm{mEq} / \mathrm{L} \text { on two } \\
\text { consecutive occasions, } \\
n(\%)\end{array}$ \\
\hline J203 [131]/J301 [25] & $\begin{array}{l}\text { Fixed dose } \mathrm{e}^{\mathrm{b}} \\
1.25-5 \mathrm{mg}\end{array}$ & No & 924 & $30(3.2)$ & $6(0.6)$ \\
\hline J302 [27] & $\begin{array}{l}\text { Incremental dose } \\
2.5-5 \mathrm{mg}^{\mathrm{c}}\end{array}$ & No & 368 & $20(5.4)$ & $4(1.1)$ \\
\hline J306 [26] & $\begin{array}{l}\text { Incremental dose } \\
1.25-5 \mathrm{mg}^{\mathrm{c}}\end{array}$ & Yes & 51 & $2(3.9)$ & $1(2.0)$ \\
\hline
\end{tabular}

Patients receiving esaxerenone in each study were included; patients receiving placebo and other drugs were excluded. J203 was a randomized, double-blind, placebo-controlled, phase II clinical study in patients with essential hypertension. J204 was a randomized, double-blind, placebocontrolled, phase II clinical study in patients with type 2 diabetes with microalbuminuria. The patient populations for the other studies are noted in earlier tables

$e G F R$ estimated glomerular filtration rate

ancludes all patients with serum potassium elevation, whether or not elevated potassium was reported as a side effect

${ }^{\mathrm{b}}$ Non-approved administration regimen

${ }^{\mathrm{c}}$ Combination treatment with CCB or RAS inhibitor 
Table 4 Reduction of serum potassium elevation by gradually increasing doses ${ }^{\mathrm{a}}$

\begin{tabular}{|c|c|c|c|c|}
\hline \multirow[b]{2}{*}{ Esaxerenone dosage (mg/day) } & \multirow{2}{*}{$\begin{array}{l}\text { Incremental dose } \\
\text { Total } 1.25-5\end{array}$} & \multicolumn{3}{|l|}{ Fixed dose $e^{b}$} \\
\hline & & 1.25 & 2.5 & 5 \\
\hline Other antihypertensive drugs & $\mathrm{ARB}$ or $\mathrm{ACE}$ inhibitor & \multicolumn{3}{|c|}{$\mathrm{ARB}$ or $\mathrm{ACE}$ inhibitor } \\
\hline Study name & J306 [26] & \multicolumn{3}{|l|}{ J204 [126] } \\
\hline Total $N$ & 51 & 70 & 68 & 69 \\
\hline Number of patients with adverse events & $25(49.0)$ & $48(68.6)$ & $46(67.6)$ & $44(63.8)$ \\
\hline Serum potassium $\geq 5.5 \mathrm{mEq} / \mathrm{L}$ & $2(3.9)$ & $8(11.4)$ & $9(13.2)$ & $14(20.3)$ \\
\hline $\begin{array}{l}\text { Serum potassium } \geq 6.0 \text { or } \geq 5.5 \mathrm{mEq} / \mathrm{L} \text { on two } \\
\text { consecutive occasions }\end{array}$ & $1(2.0)$ & $2(2.9)$ & $2(2.9)$ & $7(10.1)$ \\
\hline
\end{tabular}

Data are shown as $n(\%)$

$A R B$ angiotensin II-receptor blockers, $A C E$ angiotensin-converting enzyme

${ }^{a}$ Includes all patients with serum potassium elevation, whether or not elevated potassium was reported as a side effect

${ }^{\mathrm{b}}$ Non-approved administration regimen

\section{Conclusions}

MR blockers, including the new agent esaxerenone, have antihypertensive activity and organ protective effects. However, a careful approach to therapy and proper management of serum potassium is required to ensure safe clinical use of these agents. This includes awareness of atrisk patient groups, choosing appropriate dosages for therapy initiation and dosage titration, and monitoring of serum potassium during therapy. It is important that physicians take these important factors into consideration to optimize MR blocker therapy in patients with hypertension.

Acknowledgements The authors would like to thank Nicola Ryan, BSc, and Sally-Anne Mitchell, PhD, of Edanz Evidence Generation for providing medical writing services, which were funded by Daiichi Sankyo Co., Ltd.

Funding The development of this review article was funded by Daiichi Sankyo Co., Ltd.

\section{Compliance with ethical standards}

Conflict of interest HR declares that he has no conflicts of interest. SY and KS are employees of Daiichi Sankyo Co., Ltd.

Publisher's note Springer Nature remains neutral with regard to jurisdictional claims in published maps and institutional affiliations.

Open Access This article is licensed under a Creative Commons Attribution 4.0 International License, which permits use, sharing, adaptation, distribution and reproduction in any medium or format, as long as you give appropriate credit to the original author(s) and the source, provide a link to the Creative Commons license, and indicate if changes were made. The images or other third party material in this article are included in the article's Creative Commons license, unless indicated otherwise in a credit line to the material. If material is not included in the article's Creative Commons license and your intended use is not permitted by statutory regulation or exceeds the permitted use, you will need to obtain permission directly from the copyright holder. To view a copy of this license, visit http://creativecommons. org/licenses/by/4.0/.

\section{References}

1. Chapman N, Dobson J, Wilson S, Dahlof B, Sever PS, Wedel H, et al. Effect of spironolactone on blood pressure in subjects with resistant hypertension. Hypertension. 2007;49:839-45.

2. Zannad F, McMurray JJ, Krum H, van Veldhuisen DJ, Swedberg $\mathrm{K}$, Shi $\mathrm{H}$, et al. Eplerenone in patients with systolic heart failure and mild symptoms. N. Engl J Med. 2011;364:11-21.

3. Eguchi K, Kabutoya T, Hoshide S, Ishikawa S, Kario K. Add-on use of eplerenone is effective for lowering home and ambulatory blood pressure in drug-resistant hypertension. J Clin Hypertens. 2016;18:1250-7.

4. Nishizaka MK, Zaman MA, Calhoun DA. Efficacy of low-dose spironolactone in subjects with resistant hypertension. Am J Hypertens. 2003;16:925-30.

5. Pitt B, Remme W, Zannad F, Neaton J, Martinez F, Roniker B, et al. Eplerenone, a selective aldosterone blocker, in patients with left ventricular dysfunction after myocardial infarction. N Engl J Med. 2003;348:1309-21.

6. Pitt B, Zannad F, Remme WJ, Cody R, Castaigne A, Perez A, et al. The effect of spironolactone on morbidity and mortality in patients with severe heart failure. Randomized Aldactone Evaluation Study Investigators. $\mathrm{N}$ Engl J Med. 1999;341:709-17.

7. Weinberger MH, Roniker B, Krause SL, Weiss RJ. Eplerenone, a selective aldosterone blocker, in mild-to-moderate hypertension. Am J Hypertens. 2002;15:709-16.

8. Williams B, MacDonald TM, Morant S, Webb DJ, Sever P, McInnes G, et al. Spironolactone versus placebo, bisoprolol, and doxazosin to determine the optimal treatment for drug-resistant hypertension (PATHWAY-2): a randomised, double-blind, crossover trial. Lancet. 2015;386:2059-68.

9. Bakris GL, Agarwal R, Chan JC, Cooper ME, Gansevoort RT, Haller $\mathrm{H}$, et al. Effect of finerenone on albuminuria in patients with diabetic nephropathy: a randomized clinical trial. JAMA. 2015;314:884-94.

10. Noubiap JJ, Nansseu JR, Nyaga UF, Sime PS, Francis I, Bigna JJ. Global prevalence of resistant hypertension: a meta-analysis of data from 3.2 million patients. Heart. 2019;105:98-105. 
11. Colussi G, Catena C, Sechi LA. Spironolactone, eplerenone and the new aldosterone blockers in endocrine and primary hypertension. J Hypertens. 2013;31:3-15.

12. Pfizer. Aldactone spironolactone tablets, USP. Prescribing information. New York: Pfizer; 2008. https://www.accessdata. fda.gov/drugsatfda_docs/label/2008/012151s062lbl.pdf.

13. Sato A. Mineralocorticoid receptor antagonists: their use and differentiation in Japan. Hypertens Res. 2013;36:185-90.

14. Pelliccia F, Patti G, Rosano G, Greco C, Gaudio C. Efficacy and safety of eplerenone in the management of mild to moderate arterial hypertension: systematic review and meta-analysis. Int $\mathbf{J}$ Cardiol. 2014;177:219-28.

15. Roush GC, Ernst ME, Kostis JB, Yeasmin S, Sica DA. Dose doubling, relative potency, and dose equivalence of potassiumsparing diuretics affecting blood pressure and serum potassium: systematic review and meta-analyses. J Hypertens. 2016;34:11-9.

16. Pfizer. INSPRA ${ }^{\oplus}$ (eplerenone) tablets, for oral use. Prescribing information. New York: Pfizer; 2018. https://www.accessdata. fda.gov/drugsatfda_docs/label/2018/021437s015lbl.pdf.

17. Arai K, Tsuruoka H, Homma T. CS-3150, a novel non-steroidal mineralocorticoid receptor antagonist, prevents hypertension and cardiorenal injury in Dahl salt-sensitive hypertensive rats. Eur J Pharm. 2015;769:266-73.

18. Kato M, Furuie H, Shimizu T, Miyazaki A, Kobayashi F, Ishizuka $\mathrm{H}$. Single- and multiple-dose escalation study to assess pharmacokinetics, pharmacodynamics and safety of oral esaxerenone in healthy Japanese subjects. Br J Clin Pharm. 2018;84:1821-9.

19. Kolkhof P, Barfacker L. 30 years of the mineralocorticoid receptor: Mineralocorticoid receptor antagonists: 60 years of research and development. J Endocrinol. 2017;234:T125-40.

20. Sueta D, Yamamoto E, Tsujita K. Mineralocorticoid receptor blockers: novel selective nonsteroidal mineralocorticoid receptor antagonists. Curr Hypertens Rep. 2020;22:21.

21. Whittaker A, Kragh AM, Hartleib-Geschwindner J, Albayaty M, Backlund A, Greasley PJ, et al. Safety, tolerability, and pharmacokinetics of the mineralocorticoid receptor modulator AZD9977 in healthy men: a phase I multiple ascending dose study. Clin Transl Sci. 2020;13:275-83.

22. Daiichi-Sankyo. Minnebro (esaxerenone) tablets $1.25 \mathrm{mg}, 2.5 \mathrm{mg}$, $5 \mathrm{mg}$. Package insert. Tokyo: Daiichi-Sankyo; 2020. https://pins.ja pic.or.jp/pdf/newPINS/00067892.pdf.

23. Duggan S. Esaxerenone: first global approval. Drugs. 2019;79: 477-81.

24. Arai K, Homma T, Morikawa Y, Ubukata N, Tsuruoka H, Aoki $\mathrm{K}$, et al. Pharmacological profile of CS-3150, a novel, highly potent and selective non-steroidal mineralocorticoid receptor antagonist. Eur J Pharm. 2015;761:226-34.

25. Ito S, Itoh H, Rakugi H, Okuda Y, Yoshimura M, Yamakawa S. Double-blind randomized phase 3 study comparing esaxerenone (CS-3150) and eplerenone in patients with essential hypertension (ESAX-HTN study). Hypertension. 2020;75:51-8.

26. Itoh $\mathrm{H}$, Ito $\mathrm{S}$, Rakugi $\mathrm{H}$, Okuda $\mathrm{Y}$, Nishioka S. Efficacy and safety of dosage-escalation of low-dosage esaxerenone added to a RAS inhibitor in hypertensive patients with type 2 diabetes and albuminuria: a single-arm, open-label study. Hypertens Res. 2019;42:1572-81.

27. Rakugi H, Ito S, Itoh H, Okuda Y, Yamakawa S. Long-term phase 3 study of esaxerenone as mono or combination therapy with other antihypertensive drugs in patients with essential hypertension. Hypertens Res. 2019;42:1932-41.

28. Rakugi H, Ito S, Ito H, Okuda Y, Iijima S. The efficacy and safety of esaxerenone for patients with grade III hypertension. Prog Med. 2020;40:755-60.

29. Lainscak M, Pelliccia F, Rosano G, Vitale C, Schiariti M, Greco $\mathrm{C}$, et al. Safety profile of mineralocorticoid receptor antagonists: Spironolactone and eplerenone. Int J Cardiol. 2015;200:25-9.
30. Sica DA. Mineralocorticoid receptor antagonists for treatment of hypertension and heart failure. Methodist Debakey Cardiovasc J. 2015;11:235-9.

31. Juurlink DN, Mamdani MM, Lee DS, Kopp A, Austin PC, Laupacis A, et al. Rates of hyperkalemia after publication of the Randomized Aldactone Evaluation Study. N. Engl J Med. 2004;351:543-51.

32. Japan Pharmaceuticals and Medical Devices Agency. Pharmaceutical interview: esaxerenone $1.25 \mathrm{mg}, 2.5 \mathrm{mg}, 5 \mathrm{mg}$. Tokyo: Japan Pharmaceuticals and Medical Devices Agency; 2020. http://www.info. pmda.go.jp/go/interview/1/430574_2149049F1027_1_MN4_1F.

33. Soar J, Perkins GD, Abbas G, Alfonzo A, Barelli A, Bierens JJ, et al. European Resuscitation Council Guidelines for Resuscitation 2010 Section 8. Cardiac arrest in special circumstances: electrolyte abnormalities, poisoning, drowning, accidental hypothermia, hyperthermia, asthma, anaphylaxis, cardiac surgery, trauma, pregnancy, electrocution. Resuscitation. 2010;81:1400-33.

34. Guidelines 2000 for cardiopulmonary resuscitation and emergency cardiovascular care. Part 8: Advanced challenges in resuscitation: Section 1: Life-threatening electrolyte abnormalities. The American Heart Association in collaboration with the International Liaison Committee on Resuscitation. Circulation. 2000;102:I217-22.

35. Japanese Ministry of Health, Labor and Welfare. The Serious Side Effects Comprehensive Measures Study Group. Classification criteria for the seriousness of adverse drug reactions of medical agents. No. 80. Japanese Ministry of Health, Labor and Welfare. 1992. https://www.mhlw.go.jp/content/11121000/ 000529049.pdf.

36. The Japanese Society of Nephrology. Evidence-based clinical practice guideline for CKD. Tokyo: The Japanese Society of Nephrology; 2018. https://cdn.jsn.or.jp/data/CKD2018.pdf.

37. Montague BT, Ouellette JR, Buller GK. Retrospective review of the frequency of ECG changes in hyperkalemia. Clin J Am Soc Nephrol. 2008;3:324-30.

38. Macdonald JE, Struthers AD. What is the optimal serum potassium level in cardiovascular patients? J Am Coll Cardiol. 2004;43:155-61.

39. Campese VM, Adenuga G. Electrophysiological and clinical consequences of hyperkalemia. Kidney Int Suppl (2011). 2016;6:16-19.

40. Freeman SJ, Fale AD. Muscular paralysis and ventilatory failure caused by hyperkalaemia. Br J Anaesth. 1993;70:226-7.

41. Goyal A, Spertus JA, Gosch K, Venkitachalam L, Jones PG, Van den Berghe G, et al. Serum potassium levels and mortality in acute myocardial infarction. JAMA. 2012;307:157-64.

42. Montford JR, Linas S. How dangerous Is hyperkalemia? J Am Soc Nephrol. 2017;28:3155-65.

43. Palmer BF, Clegg DJ. Physiology and pathophysiology of potassium homeostasis. Adv Physiol Educ. 2016;40:480-90.

44. Palmer BF, Clegg DJ. Physiology and pathophysiology of potassium homeostasis: core curriculum 2019. Am J Kidney Dis. 2019;74:682-95.

45. Comi G, Testa D, Cornelio F, Comola M, Canal N. Potassium depletion myopathy: a clinical and morphological study of six cases. Muscle Nerve. 1985;8:17-21.

46. Marti G, Schwarz C, Leichtle AB, Fiedler GM, Arampatzis S, Exadaktylos AK, et al. Etiology and symptoms of severe hypokalemia in emergency department patients. Eur J Emerg Med. 2014;21:46-51.

47. Shintani S, Shiigai T, Tsukagoshi H. Marked hypokalemic rhabdomyolysis with myoglobinuria due to diuretic treatment. Eur Neurol. 1991;31:396-8.

48. Krogager ML, Torp-Pedersen C, Mortensen RN, Kober L, Gislason G, Sogaard P, et al. Short-term mortality risk of serum potassium levels in hypertension: a retrospective analysis of nationwide registry data. Eur Heart J. 2017;38:104-12. 
49. Luo J, Brunelli SM, Jensen DE, Yang A. Association between serum potassium and outcomes in patients with reduced kidney function. Clin J Am Soc Nephrol. 2016;11:90-100.

50. An JN, Lee JP, Jeon HJ, Kim DH, Oh YK, Kim YS, et al. Severe hyperkalemia requiring hospitalization: predictors of mortality. Crit Care. 2012;16:R225.

51. Kashihara N, Kohsaka S, Kanda E, Okami S, Yajima T. Hyperkalemia in real-world patients under continuous medical care in Japan. Kidney Int Rep. 2019;4:1248-60.

52. Ahmed A, Zannad F, Love TE, Tallaj J, Gheorghiade M, Ekundayo OJ, et al. A propensity-matched study of the association of low serum potassium levels and mortality in chronic heart failure. Eur Heart J. 2007;28:1334-43.

53. Bowling CB, Pitt B, Ahmed MI, Aban IB, Sanders PW, Mujib $\mathrm{M}$, et al. Hypokalemia and outcomes in patients with chronic heart failure and chronic kidney disease: findings from propensity-matched studies. Circ Heart Fail. 2010;3: 253-60.

54. Aldahl M, Jensen AC, Davidsen L, Eriksen MA, Moller Hansen $\mathrm{S}$, Nielsen BJ, et al. Associations of serum potassium levels with mortality in chronic heart failure patients. Eur Heart J. 2017;38: 2890-6.

55. Krijthe BP, Heeringa J, Kors JA, Hofman A, Franco OH, Witteman JC, et al. Serum potassium levels and the risk of atrial fibrillation: the Rotterdam Study. Int J Cardiol. 2013;168: 5411-5.

56. Widimsky P. Hypokalemia and the heart. E-J Cardiol Pr. 2008;7:9. https://www.escardio.org/Journals/E-Journal-of-Cardiology-Pra ctice/Volume-7/Hypokalemia-and-the-heart.

57. Jain N, Kotla S, Little BB, Weideman RA, Brilakis ES, Reilly $\mathrm{RF}$, et al. Predictors of hyperkalemia and death in patients with cardiac and renal disease. Am J Cardiol. 2012;109:1510-3.

58. Hollander-Rodriguez JC, Calvert JF Jr. Hyperkalemia. Am Fam Physician. 2006;73:283-90.

59. Ben Salem C, Badreddine A, Fathallah N, Slim R, Hmouda H. Drug-induced hyperkalemia. Drug Saf. 2014;37:677-92.

60. Zacchia M, Abategiovanni ML, Stratigis S, Capasso G. Potassium: from physiology to clinical implications. Kidney Dis (Basel). 2016;2:72-9.

61. Drawz PE, Babineau DC, Rahman M. Metabolic complications in elderly adults with chronic kidney disease. J Am Geriatr Soc. 2012;60:310-5.

62. Weinberg JM, Appel LJ, Bakris G, Gassman JJ, Greene T, Kendrick CA, et al. Risk of hyperkalemia in nondiabetic patients with chronic kidney disease receiving antihypertensive therapy. Arch Intern Med. 2009;169:1587-94.

63. Heshka J, Ruzicka M, Hiremath S, McCormick BB. Spironolactone for difficult to control hypertension in chronic kidney disease: an analysis of safety and efficacy. J Am Soc Hypertens. 2010;4:295-301.

64. Raebel MA, Ross C, Xu S, Roblin DW, Cheetham C, Blanchette $\mathrm{CM}$, et al. Diabetes and drug-associated hyperkalemia: effect of potassium monitoring. J Gen Intern Med. 2010;25:326-33.

65. Collins AJ, Pitt B, Reaven N, Funk S, McGaughey K, Wilson D, et al. Association of serum potassium with all-cause mortality in patients with and without heart failure, chronic kidney disease, and/or diabetes. Am J Nephrol. 2017;46:213-21.

66. Loutradis C, Tolika P, Skodra A, Avdelidou A, Sarafidis PA. Prevalence of hyperkalemia in diabetic and non-diabetic patients with chronic kidney disease: a nested case-control study. Am J Nephrol. 2015;42:351-60.

67. Thomsen RW, Nicolaisen SK, Adelborg K, Svensson E, Hasvold $\mathrm{P}$, Palaka E, et al. Hyperkalaemia in people with diabetes: occurrence, risk factors and outcomes in a Danish populationbased cohort study. Diabet Med. 2018;35:1051-60.
68. Dharmarajan K, Rich MW. Epidemiology, pathophysiology, and prognosis of heart failure in older adults. Heart Fail Clin. 2017;13:417-26.

69. Schefold JC, Filippatos G, Hasenfuss G, Anker SD, von Haehling S. Heart failure and kidney dysfunction: epidemiology, mechanisms and management. Nat Rev Nephrol. 2016;12: 610-23.

70. Di Lullo L, Ronco C, Granata A, Paoletti E, Barbera V, Cozzolino $\mathrm{M}$, et al. Chronic hyperkalemia in cardiorenal patients: risk factors, diagnosis, and new treatment options. Cardiorenal Med. 2019;9:8-21.

71. Tromp J, van der Meer P. Hyperkalaemia: aetiology, epidemiology, and clinical significance. Eur Heart J Suppl. 2019;21:A6-A11.

72. Sarwar CM, Papadimitriou L, Pitt B, Pina I, Zannad F, Anker SD, et al. Hyperkalemia in heart failure. J Am Coll Cardiol. 2016;68:1575-89.

73. Schwinger RH, Erdmann E. Heart failure and electrolyte disturbances. Methods Find Exp Clin Pharm. 1992;14:315-25.

74. Michel A, Martin-Perez M, Ruigomez A, Garcia Rodriguez LA. Risk factors for hyperkalaemia in a cohort of patients with newly diagnosed heart failure: a nested case-control study in UK general practice. Eur J Heart Fail. 2015;17:205-13.

75. Berliner RW. Renal mechanisms for potassium excretion. Harvey Lect. 1961;55:141-71.

76. Adler S, Lindeman RD, Yiengst MJ, Beard E, Shock NW. Effect of acute acid loading on urinary acid excretion by the aging human kidney. J Lab Clin Med. 1968;72:278-89.

77. Shannon RP, Minaker KL, Rowe JW. Aging and water balance in humans. Semin Nephrol. 1984;4:346-53.

78. Kumar R, Kanev L, Woods SD, Brenner M, Smith B. Managing hyperkalemia in high-risk patients in long-term care. Am J Manag Care. 2017;23:S27-36.

79. Nunez J, Bayes-Genis A, Zannad F, Rossignol P, Nunez E, Bodi $\mathrm{V}$, et al. Long-term potassium monitoring and dynamics in heart failure and risk of mortality. Circulation. 2018;137:1320-30.

80. Raebel MA. Hyperkalemia associated with use of angiotensinconverting enzyme inhibitors and angiotensin receptor blockers. Cardiovasc Ther. 2012;30:e156-66.

81. Roscioni SS, de Zeeuw D, Bakker SJ, Lambers Heerspink HJ. Management of hyperkalaemia consequent to mineralocorticoidreceptor antagonist therapy. Nat Rev Nephrol. 2012;8:691-9.

82. Buchner N, Banas B, Kramer BK. Telmisartan, ramipril, or both in patients at high risk of vascular events. $\mathrm{N}$ Engl $\mathrm{J}$ Med. 2008;359:426.

83. Feng Y, Huang R, Kavanagh J, Li L, Zeng X, Li Y, et al. Efficacy and safety of dual blockade of the renin-angiotensinaldosterone system in diabetic kidney disease: a meta-analysis. Am J Cardiovasc Drugs. 2019;19:259-86.

84. MacKinnon M, Shurraw S, Akbari A, Knoll GA, Jaffey J, Clark HD. Combination therapy with an angiotensin receptor blocker and an ACE inhibitor in proteinuric renal disease: a systematic review of the efficacy and safety data. Am J Kidney Dis. 2006;48:8-20.

85. Alderman MH, Piller LB, Ford CE, Probstfield JL, Oparil S, Cushman WC, et al. Clinical significance of incident hypokalemia and hyperkalemia in treated hypertensive patients in the antihypertensive and lipid-lowering treatment to prevent heart attack trial. Hypertension. 2012;59:926-33.

86. Williams GH, Burgess E, Kolloch RE, Ruilope LM, Niegowska $\mathrm{J}$, Kipnes MS, et al. Efficacy of eplerenone versus enalapril as monotherapy in systemic hypertension. Am J Cardiol. 2004;93: 990-6.

87. Schjoedt KJ, Rossing K, Juhl TR, Boomsma F, Tarnow L, Rossing $\mathrm{P}$, et al. Beneficial impact of spironolactone on nephrotic range albuminuria in diabetic nephropathy. Kidney Int. 2006;70:536-42. 
88. van den Meiracker AH, Baggen RG, Pauli S, Lindemans A, Vulto AG, Poldermans D, et al. Spironolactone in type 2 diabetic nephropathy: efects on proteinuria, blood pressure and renal function. J Hypertens. 2006;24:2285-92.

89. Imai E, Chan JC, Ito S, Yamasaki T, Kobayashi F, Haneda M, et al. Effects of olmesartan on renal and cardiovascular outcomes in type 2 diabetes with overt nephropathy: a multicentre, randomised, placebo-controlled study. Diabetologia. 2011;54:2978-86.

90. Sadjadi SA, McMillan JI, Jaipaul N, Blakely P, Hline SS. A comparative study of the prevalence of hyperkalemia with the use of angiotensin-converting enzyme inhibitors versus angiotensin receptor blockers. Ther Clin Risk Manag. 2009;5:547-52.

91. Zheng SL, Roddick AJ, Ayis S. Effects of aliskiren on mortality, cardiovascular outcomes and adverse events in patients with diabetes and cardiovascular disease or risk: a systematic review and meta-analysis of 13,395 patients. Diab Vasc Dis Res. 2017; 14:400-6.

92. SOLVD Investigators, Yusuf S, Pitt B, Davis CE, Hood WB, Cohn JN. Effect of enalapril on survival in patients with reduced left ventricular ejection fractions and congestive heart failure. $\mathrm{N}$ Engl J Med. 1991;325:293-302.

93. Granger CB, McMurray JJ, Yusuf S, Held P, Michelson EL, Olofsson B, et al. Effects of candesartan in patients with chronic heart failure and reduced left-ventricular systolic function intolerant to angiotensin-converting-enzyme inhibitors: the CHARMAlternative trial. Lancet. 2003;362:772-6.

94. Mehdi UF, Adams-Huet B, Raskin P, Vega GL, Toto RD. Addition of angiotensin receptor blockade or mineralocorticoid antagonism to maximal angiotensin-converting enzyme inhibition in diabetic nephropathy. J Am Soc Nephrol. 2009;20:2641-50.

95. Bianchi S, Bigazzi R, Campese VM. Long-term effects of spironolactone on proteinuria and kidney function in patients with chronic kidney disease. Kidney Int. 2006;70:2116-23.

96. Chrysostomou A, Pedagogos E, MacGregor L, Becker GJ. Doubleblind, placebo-controlled study on the effect of the aldosterone receptor antagonist spironolactone in patients who have persistent proteinuria and are on long-term angiotensin-converting enzyme inhibitor therapy, with or without an angiotensin II receptor blocker. Clin J Am Soc Nephrol. 2006;1:256-62.

97. Furumatsu Y, Nagasawa Y, Tomida K, Mikami S, Kaneko T, Okada N, et al. Effect of renin-angiotensin-aldosterone system triple blockade on non-diabetic renal disease: addition of an aldosterone blocker, spironolactone, to combination treatment with an angiotensin-converting enzyme inhibitor and angiotensin II receptor blocker. Hypertens Res. 2008;31:59-67.

98. Rossing K, Schjoedt KJ, Smidt UM, Boomsma F, Parving HH. Beneficial effects of adding spironolactone to recommended antihypertensive treatment in diabetic nephropathy: a randomized, double-masked, cross-over study. Diabetes Care. 2005; 28:2106-12.

99. Schjoedt KJ, Rossing K, Juhl TR, Boomsma F, Rossing P, Tarnow L, et al. Beneficial impact of spironolactone in diabetic nephropathy. Kidney Int. 2005;68:2829-36.

100. Tylicki L, Rutkowski P, Renke M, Larczynski W, Aleksandrowicz E, Lysiak-Szydlowska W, et al. Triple pharmacological blockade of the renin-angiotensin-aldosterone system in nondiabetic CKD: an open-label crossover randomized controlled trial. Am J Kidney Dis. 2008;52:486-93.

101. Bianchi S, Bigazzi R, Campese VM. Antagonists of aldosterone and proteinuria in patients with CKD: an uncontrolled pilot study. Am J Kidney Dis. 2005;46:45-51.

102. Gonzalez Monte E, Andres A, Polanco N, Toribio MJ, Santana $\mathrm{R}$, Gutierrez Martinez E, et al. Addition of spironolactone to dual blockade of renin angiotensin system dramatically reduces severe proteinuria in renal transplant patients: an uncontrolled pilot study at 6 months. Transpl Proc. 2010;42:2899-901.
103. Sato A, Hayashi K, Saruta T. Antiproteinuric effects of mineralocorticoid receptor blockade in patients with chronic renal disease. Am J Hypertens. 2005;18:44-9.

104. Sengul E, Sahin T, Sevin E, Yilmaz A. Effect of spironolactone on urinary protein excretion in patients with chronic kidney disease. Ren Fail. 2009;31:928-32.

105. Nilsson E, Gasparini A, Arnlov J, Xu H, Henriksson KM, Coresh $\mathrm{J}$, et al. Incidence and determinants of hyperkalemia and hypokalemia in a large healthcare system. Int J Cardiol. 2017;245:277-84.

106. Kidney Disease Outcomes Quality Initiative. K/DOQI clinical practice guidelines on hypertension and antihypertensive agents in chronic kidney disease. Am J Kidney Dis. 2004;43:S1-290.

107. Writing Committee Members, Yancy CW, Jessup M, Bozkurt B, Butler J, Casey DE Jr., et al. 2013 ACCF/AHA guideline for the management of heart failure: a report of the American College of Cardiology Foundation/American Heart Association Task Force on practice guidelines. Circulation. 2013;128:e240-327.

108. Tsutsui $\mathrm{H}$, Isobe $\mathrm{M}$, Ito $\mathrm{H}$, Ito $\mathrm{H}$, Okumura $\mathrm{K}$, Ono $\mathrm{M}$, et al. JCS 2017/JHFS 2017 guideline on diagnosis and treatment of acute and chronic heart failure-digest version. Circ J. 2019; 83:2084-184.

109. Hira K, Aoki N, Fukui T. Pseudohyperkalaemia at commercial laboratories in Japan: a questionnaire survey. Ann Clin Biochem. 2004:41:155-6.

110. Asirvatham JR, Moses V, Bjornson L. Errors in potassium measurement: a laboratory perspective for the clinician. $\mathrm{N}$ Am J Med Sci. 2013;5:255-9.

111. Ismail A, Shingler W, Seneviratne J, Burrows G. In vitro and in vivo haemolysis and potassium measurement. BMJ. 2005;330:949.

112. Epstein M, Calhoun DA. Aldosterone blockers (mineralocorticoid receptor antagonism) and potassium-sparing diuretics. J Clin Hypertens (Greenwich). 2011;13:644-8.

113. Cupisti A, Kovesdy CP, D'Alessandro C, Kalantar-Zadeh K. Dietary approach to recurrent or chronic hyperkalaemia in patients with decreased kidney function. Nutrients. 2018;10:261. https://doi.org/10.3390/nu10030261.

114. The Japanese Society of Nephrology. Dietary recommendations for chronic kidney disease. Jpn J Nephrol. 2014;56:553-99. https://cdn.jsn.or.jp/guideline/pdf/CKD-Dietaryrecommenda tions2014.pdf.

115. National Kidney Foundation. Clinical practice guideline for nutrition in chronic kidney disease: 2019 update. National Kidney Foundation. 2019. https://www.kidney.org/sites/default/files/ Nutrition_GL\%2BSubmission_101719_Public_Review_Copy.pdf.

116. Ministry of Education, Culture, Sports, Science and Technology - Japan. Standards tables of food composition in Japan. 7th edition. In: Ministry of Education, Culture, Sports, Science and Technology—Japan. Tokyo; 2015. https://www.mext.go.jp/ component/english/_icsFiles/afieldfile/2017/12/25/1374049_ 1 r12 1.xlsx.

117. Iorember FM. Malnutrition in chronic kidney disease. Front Pediatr. 2018;6:161.

118. Lewis JL. Hyperkalemia. 2020. https://www.msdmanuals.com/ professional/endocrine-and-metabolic-disorders/electrolytedisorders/hyperkalemia. Accessed 27 Oct 2020.

119. Dunn JD, Benton WW, Orozco-Torrentera E, Adamson RT. The burden of hyperkalemia in patients with cardiovascular and renal disease. Am J Manag Care. 2015;21:s307-15.

120. Rossignol P, Legrand M, Kosiborod M, Hollenberg SM, Peacock WF, Emmett M, et al. Emergency management of severe hyperkalemia: guideline for best practice and opportunities for the future. Pharm Res. 2016;113:585-91.

121. White WB, Duprez D, St Hillaire R, Krause S, Roniker B, KuseHamilton $\mathrm{J}$, et al. Effects of the selective aldosterone blocker eplerenone versus the calcium antagonist amlodipine in systolic hypertension. Hypertension. 2003;41:1021-6. 
122. Krum H, Nolly H, Workman D, He W, Roniker B, Krause S, et al. Efficacy of eplerenone added to renin-angiotensin blockade in hypertensive patients. Hypertension. 2002;40:117-23.

123. Rossignol P, Dobre D, McMurray JJ, Swedberg K, Krum H, van Veldhuisen DJ, et al. Incidence, determinants, and prognostic significance of hyperkalemia and worsening renal function in patients with heart failure receiving the mineralocorticoid receptor antagonist eplerenone or placebo in addition to optimal medical therapy: results from the Eplerenone in Mild Patients Hospitalization and Survival Study in Heart Failure (EMPHASIS-HF). Circ Heart Fail. 2014;7:51-8.

124. Tsutsui H, Ito H, Kitakaze M, Komuro I, Murohara T, Izumi T, et al. Double-blind, randomized, placebo-controlled trial evaluating the efficacy and safety of eplerenone in Japanese patients with chronic heart failure (J-EMPHASIS-HF). Circ J. 2017;82:148-58.

125. Edwards NC, Steeds RP, Chue CD, Stewart PM, Ferro CJ, Townend JN. The safety and tolerability of spironolactone in patients with mild to moderate chronic kidney disease. Br J Clin Pharm. 2012;73:447-54.

126. Ito S, Shikata K, Nangaku M, Okuda Y, Sawanobori T. Efficacy and safety of esaxerenone (CS-3150) for the treatment of type 2 diabetes with microalbuminuria: a randomized, double-blind, placebo-controlled, phase II trial. Clin J Am Soc Nephrol. 2019;14:1161-72.

127. Kurata A, Yoshida T, Inoue M, Ishizuka T, Nakatsu T, Shimizu $\mathrm{T}$, et al. Pharmacokinetics and safety of single-dose esaxerenone in Japanese subjects with mild to moderate hepatic impairment. Adv Ther. 2020;37:253-64.

128. Brown NJ. Eplerenone: cardiovascular protection. Circulation. 2003;107:2512-8.

129. Fukae M, Jamsen K, Shimizu T, Yoshimura M, Yin O, Kastrissios $\mathrm{H}$, et al. Exposure-response analyses for efficacy and safety of esaxerenone, a novel nonsteroidal mineralocorticoid receptor blocker. ACoP10, Orlando, FL. 2019;1:M-014. https://www.go-acop.org/assets/ACoP10/documents/ACoP10\% 20Combined\%20Abstracts_2019.pdf.

130. Levy DG, Rocha R, Funder JW. Distinguishing the antihypertensive and electrolyte effects of eplerenone. J Clin Endocrinol Metab. 2004;89:2736-40.

131. Ito S, Itoh H, Rakugi H, Okuda Y, Yamakawa S. Efficacy and safety of esaxerenone (CS-3150) for the treatment of essential hypertension: a phase 2 randomized, placebo-controlled, doubleblind study. J Hum Hypertens. 2019;33:542-51. 